\title{
A PROTEÇÃO SÓCIO-LABORAL DAS TRABALHADORAS E DOS TRABALHADORES A TEMPO PARCIAL NA ESPANHA SEGUNDO O MARCO DA FLEXISEGURANÇA: GARANTIA EFETIVA OU ÉTICA OPACA?
}

\author{
Social and labour protection of part-time workers in Spain in a framework \\ of flexicurity: effective guarantee or opaque ethics?
}

\section{Sheila Stolz}

Professora da Faculdade de Direito da Universidade Federal do Rio Grande (FADIR/ FURG/RS). Mestre em Direito pela Universitat Pompeu Fabra (UPF/Barcelona/ Espanha). Doutoranda em Direito pela Pontifícia Universidade Católica do Rio Grande do Sul (PUC/RS). Coordenadora Geral do Núcleo de Pesquisa e Extensão em Direitos Humanos (NUPEDH/FURG), Coordenadora do Curso de Pós-Graduação em Educação em Direitos Humanos (PGEDH/FURG-UAB-CAPES) e pesquisadora do Grupo de Pesquisa Estado, Processo e Sindicalismo. E-mail: sheilastolz@furg.br

\section{Rodrigo Wasem Galia}

Professor do Curso de Direito da UNISINOS/RS. Professor dos Cursos de Direito e Ciências Contábeis da Faculdades Integradas São Judas Tadeu (POA/RS). Mestre em Direito pela Pontifícia Universidade Católica do Rio Grande do Sul (PUC/RS). Doutorando em Direito pela Pontifícia Universidade Católica do Rio Grande do Sul (PUC/RS). E-mail: rodrigogalia@hotmail.com

RECEBIDO EM: 28.08.2012

APROVADO EM: 20.12.2012

\section{RESUMO}

Desde o início dos anos 80 se assiste a um alargado debate sobre como tratar o trabalho frente à notória mutação da economia motivada, entre outros fatores, pela evolução tecnológica das formas de produção que requerem novas formas de organização do trabalho e pelo incremento da globalização da economia com o respectivo surgimento de economias emergentes mais competitivas (as asiáticas, por exemplo), e, no que concerne a Europa, somam-se ainda o aumento massivo da 
imigração e a configuração de um Estado de bem-estar social que não consegue dar respostas adequadas a estas temáticas. Em consequência, surge à defesa da ideia de flexibilizar o mercado de trabalho, através da chamada desregulamentação, tornando -o, desta forma, mais adaptável aos referidos novos contextos. Considerando que o mercado de trabalho não é homogêneo, pode-se dizer que existem muitas e variadas formas de flexibilização. E se a erosão da relação convencional de trabalho é algo palpável e visível, natural que a flexibilidade se vincule às formas não convencionais de trabalho, associadas, por exemplo, ao tempo de trabalho tipificado, entre outros, no trabalho descontinuo e no trabalho a tempo parcial que, em âmbito Europeu, estão delimitados por uma série de prerrogativas de proteção social. Seja neste ou em outros exemplos, o conceito de flexibilização passa a adquirir uma nova configuração e perspectiva legal: a flexycurity (flexisegurança). Através da pesquisa realizada objetiva-se analisar qual é e também qual deve ser o significado e o conteúdo da proteção social das trabalhadoras e dos trabalhadores a tempo parcial na Espanha, partindo do papel que na atualidade desempenha e/ou deve desempenhar este tipo de trabalho naquele mercado de trabalho. Justifica-se esta escolha seja porque a flexisegurança foi indicada, entre outras instituições, pela Comissão Europeia, como forma de enfrentamento da crise sócio-econômica que desde 2009 assola a Espanha, seja porque (e também) a dramática realidade atual pode servir de parâmetro para refletir e pensar o futuro das relações de trabalho no Brasil e na América Latina.

Palavras-chave: Direito ao/do Trabalho. Flexisegurança Laboral. Proteção sóCio-laboral das trabalhadoras e dos trabalhadores. Trabalho a tempo parcial.

\begin{abstract}
Since the early 80 s we observe a broader debate about how to treat work alongside a notorious changing economy driven, among other factors, by the technological evolution of the forms of production that require new forms of work organization and the increase of economic globalization with the emergence of emerging economies more competitive (Asian, for example), and, with respect to Europe, add up even the massive increase in immigration and the setting of a state of social welfare that cannot appropriately respond to these issues. Consequently, comes to the defence of the idea of the flexible labour market, by calling deregulation, making it thus more adaptable to these new contexts. Whereas the labour market is not homogeneous, it can be said that there are many different ways of flexibility. And if the erosion of conventional relationship work is something tangible and visible, natural that flexibility is bound to unconventional forms of work, associated, for example, working time typified, among others, discontinuous and part-time jobs, in the European context, are defined by a series of powers of social protection. Whether this
\end{abstract}


or other examples, the concept of flexibility takes on a new configuration and legal perspective: the flexycurity (flexisecurity). This research aims to analyse what is and also what should be the meaning and content of the social protection of part time workers in Spain, leaving the paper that currently plays and / or should play this type of work in the labour market. This choice is justified as flexicurity was indicated, among other institutions, by the European Commission as a way of coping with the socio-economic crisis that plagues Spain since 2009, either because (and also) the dramatic current reality can serve as a parameter to reflect and think about the future of labour relations in Brazil and Latin America.

Keywords: Right to Work. Flexicurity Labour. Labour and social protecTION. PART-TIME WORK.

Sumário: Introdução. 1. A proteção social das trabalhadoras e dos trabalhadores a tempo parcial tendo como marco as atuais tendências comunitárias com vistas à flexigurança. 2. A proteção social das trabalhadoras e dos trabalhadores a tempo parcial nos ordenamentos internacional e comunitário. 2. 1. Normas de caráter internacional. 2. 2. Normas de caráter comunitário. 3. A proteção social dos trabalhadores a tempo parcial no ordenamento espanhol. Conclusão. Referências.

\section{INTRODUÇÃO}

Entre as tendências econômicas que nas últimas décadas mais influência tiveram no direito ao/do trabalho encontra-se, precisamente, a concernente as horas de trabalho que são, cada vez mais diversificadas, descentralizadas e individualizadas. Esta tendência aumentou, igualmente, as tensões entre as necessidades e as preferências das trabalhadoras e dos trabalhadores ${ }^{190}$ e as exigências dos negócios. Realidade que conduz a novas inquietudes como, por exemplo, aquelas advindas das

190 No português, assim como eu outros idiomas, é comum o uso exclusivo do gênero gramatical masculino para designar o conjunto de homens e mulheres, ainda que morfologicamente existam formas femininas. Admite-se que o gênero masculino "engloba" o feminino, como é o caso da usual utilização das expressões "o Homem" ou "os Homens" como sinônimos de "a Humanidade". Tomando a parte pelo todo, identificam-se os Homens com a universalidade dos seres humanos. Não obstante a padronizada utilização do vernáculo utilizar o gênero masculino como genérico, entende-se que subsumidas na referência linguística aos homens, as mulheres tornam-se praticamente invisíveis na linguagem e, quando visíveis, continuam marcadas por uma assimetria que as encerra numa especificidade, uma "diferença" natural (o sexo), numa "humanidade" de um outro tipo. Ademais, em se tratando das relações de trabalho onde existem reais abismos entre homens e mulheres entende-se por bem utilizar-se a linguagem aqui expressa como meio promotor da igualdade. 
desigualdades sociais relacionadas ao tempo de trabalho - particularmente no que diz respeito às mulheres - e a capacidade das trabalhadoras e dos trabalhadores de equilibrar seu trabalho remunerado e sua vida pessoal.

O tempo de trabalho faz parte da essência das relações de trabalho tanto que na primeira Conferência Internacional do Trabalho realizada, em 1919, pela Organização Internacional do Trabalho (OIT) ele, juntamente com a proteção à maternidade, a luta contra o desemprego, a definição da idade mínima de 14 anos para o trabalho na indústria e à proibição do trabalho noturno de mulheres e menores de 18 anos, configurou a primeira ${ }^{191}$ das demais Convenções Internacionais levadas a termo na referida Conferência. Inúmeras são as Convenções da OIT que sucederam esta primeira normativa internacional que tratou da matéria ${ }^{192}$ e, segundo pesquisa deste Organismo realizada pelo Programa Sobre as Condições de Trabalho e Emprego (TRAVAIL) publicados em 2007, cinco são as dimensões do trabalho descente com relação à distribuição do tempo de trabalho que, em síntese, deve: 1) promover a saúde e a segurança; 2) ser conveniente para a família (family-friendly); 3) promover a igualdade de gênero; 4) aumentar a produtividade e competitividade das empresas; e, por fim, 5) facilitar que seja a trabalhadora e o trabalhador que decida sobre suas horas de trabalho. Para promover estas cinco dimensões faz-se necessário, segundo o TRAVAIL, a criação e implantação de uma ampla gama de políticas públicas (nacionais e setoriais) que conte com o envolvimento das partes interessadas. A combinação das políticas a serem projetadas e desenvolvidas varia, ademais, de país para país, de uma região para outra dentro de um mesmo país e, também, dos vínculos que cada país possui com os blocos econômicos e políticos com que se relaciona ou faz parte.

Pelo exposto, pode-se arguir, que o próprio conceito de trabalho atravessa no presente momento uma fase de mudanças, dado que a relação institucionalizada entre oferta e procura de trabalho se organiza cada vez mais segundo novos modelos contratuais. Deste modo, torna-se também mais difícil definir o que se entende atualmente com a expressão "emprego normal e/ou típico". Sem procurar ter qualquer intenção normativa, apresentam-se, a seguir, as principais características da figura que compreende a relação contratual tradicional. Esta se baseia num modelo

191 Dita Convenção recebeu o nome de Convenção Internacional das Horas de Trabalho na indústria.

192 Entre elas, por exemplo, a Convenção Relativa ao Trabalho Noturno das Mulheres, adotada pela Conferência Geral da OIT, na sua décima oitava sessão, realizada em Genebra, em 1934 e mais recentemente a Convenção sobre o Trabalho Decente para as Trabalhadoras e Trabalhadores Domésticos, 2011 ( $n^{\circ} 189$ ), acompanhada da Recomendação ( $\left.n^{\circ} 201\right)$ que, no artigo 10, aborda a jornada de trabalho. O tema concernente a jornada de trabalho é tão fundamental que em 2007 a OIT lançou uma publicação específica sobre a questão, intitulada: Duração do trabalho em todo o mundo: tendências de jornadas de trabalho, legislação e políticas numa perspectiva comparada. Veja-se mais em: LEE, Sangheon; McCANN, Deirdre e MESSENGER, Jon (2007). 
de organização de trabalho específico caracterizado por um contrato de trabalho ${ }^{193}$ a termo indefinido normalmente rígido caracterizado, ademais, pela subordinação da trabalhadora e do trabalhador em relação ao empregador - entendido aqui como aquele responsável por definir e fiscalizar as atividades que serão realizadas pela e pelo empregada e emrpegado e que serão retribuídas com o pagamento de um salário regulamentado legal ou convencionalmente e, obrigatoriamente, com as também devidas contribuições a previdência social que lhe fazem jus.

A partir dos anos 80 quando se iniciou o debate sobre a erosão das formas normais, convencionais ou típicas de emprego, começaram então a surgir, em contraponto à forma típica de contrato de trabalho, outros tipos de relação de trabalho tais como: o trabalho temporário, os contratos de trabalho com tempo determinado, o trabalho a tempo parcial e o teletrabalho, por exemplo. Estas são algumas das designadas formas atípicas de emprego. Em relação a estas formas torna-se cada vez mais difícil avaliar que riscos e oportunidades estão a ela associadas quer em termos do indivíduo que trabalha, quer em termos daquele que o contrata, quer em termos da própria sociedade. Se por um lado as formas atípicas de emprego estão menos regulamentadas e, como tal, menos protegidas do que as ditas relações contratuais normais, por outro lado, é certo que estas formas representam ou deveriam representar (pelo menos em sua grande maioria) um período transitório para as formas típicas.

No que segue objetiva-se analisar qual é e também qual deve ser o significado e o conteúdo da proteção social das e trabalhadoras e dos trabalhadores a tempo parcial na Espanha, partindo do papel que na atualidade desempenha e/ou deve desempenhar este tipo de trabalho naquele mercado de trabalho. Justifica-se esta escolha seja porque a flexisegurança foi indicada, entre outras instituições, pela Comissão Europeia, como forma de enfrentamento da crise sócio-econômica que desde 2009 assola a Espanha, seja porque (e também) a dramática realidade atual pode servir de parâmetro para refletir e pensar o futuro das relações de trabalho no Brasil e na América Latina.

Metodologicamente, lançar-se-á mão do quadro jurídico-positivo comunitário e internacional de proteção social estabelecido para as trabalhadoras e os trabalhadores a tempo parcial, procurando, a partir deste marco, delimitar a função que desempenha a forma de modalidade contratual atípica de contrato de trabalho a tempo parcial no marco da atual política de emprego espanhola e seu regime de proteção social. Ou seja, procurar-se-á estabelecer em que medida a proteção social das trabalhadoras e dos trabalhadores a tempo parcial contribui - e pode e deve contribuir - para atingir os objetivos da política de emprego para o qual o trabalho a tempo parcial está orientado segundo as necessidades de flexibilidade que requer a política comunitária de emprego iniciada após o Tratado de Amsterdam e refletida na denominada Estratégia Européia de Emprego (EEE) ${ }^{194}$. E dado que a política de

193 Que dá origem ao que no Brasil denomina-se relação de emprego.

194 A Estratégia Europeia de Emprego proporciona um marco — um método aberto de 
emprego comunitária da União Europeia, com caráter geral, não serve apenas para o aumento quantitativo da ocupação, mas também de modo absolutamente imprescindível, para a melhoria de sua qualidade, o fomento da contratação a tempo parcial não pode supor, direta ou indiretamente, um meio de precarização das relações de trabalho. A proteção social constitui, pelo menos em fundamento, um dos elementos do regime jurídico do trabalho a tempo parcial que determina sua constituição em um emprego de qualidade e, sendo assim, um instrumento útil para evitar a exclusão social ademais de ser um catalizador da promoção da dignidade humana.

Com base nestas premissas a primeira seção deste trabalho apresentará a definição de flexigurança e sua aplicabilidade em âmbito Europeu para, na seção seguinte, abordar a proteção social das trabalhadoras e dos trabalhadores a tempo parcial tendo como marco os ordenamentos jurídicos internacionais e comunitário. A terceira seção abarcará a proteção social deste tipo de trabalho desde a perspectiva do ordenamento jurídico Espanhol.

\section{A proteção social das trabalhadoras e dos trabalhadores a tempo PARCIAL TENDO COMO MARCO AS ATUAIS TENDÊNCIAS COMUNITÁRIAS COM VISTAS À FLEXIGURANÇA}

Desde o início dos anos 80 um alargado debate sobre como tratar a questão da flexibilização do mercado de trabalho tem feito parte do cenário Europeu dado, sobretudo, a notória inadequação existente entre dito mercado e as crescentes mutações da economia (macro e micro) motivadas, entre outros fatores, pelo alargamento da evolução tecnológica das formas de produção que requerem novas formas de or-

coordenação - que permite aos países da UE compartilhar informação e debater e coordenar suas políticas de emprego. Cada ano, os governos dos países membros, através do Comitê de Emprego e as instituições, elaboram o denominado plano de medidas de emprego, formado por:"Diretrizes de emprego: orientações para as políticas de emprego dos países membros, propostas pela Comissão, acordadas pelos governos nacionais e adotados pelo Conselho que estabelece prioridades e objetivos comuns.Programas Nacionais de Reforma: informes apresentados pelos governos dos países membros, que descrevem suas políticas de emprego e que são analisadas pela Comissão para verificar sua coerência com os cinco objetivos da Europa 2020 e as sete iniciativas emblemáticas. Os cinco grandes objetivos da UE para 2020 são:1. Emprego: aumentar para 75\% a taxa de emprego na faixa etária dos 20-64 anos.2. I\&D: aumentar para 3\% do PIB o investimento da UE na I\&D. 3.Alterações climáticas e energia: reduzir as emissões de gases com efeito de estufa em $20 \%$ (ou em 30\%, se forem reunidas as condições necessárias) relativamente aos níveis registados em 1990; obter 20\% da energia a partir de fontes renováveis; aumentar em $20 \%$ a eficiência energética. 4. Educação: reduzir as taxas de abandono escolar para níveis abaixo dos 10\% aumentar para, pelo menos, $40 \%$ a percentagem da população na faixa etária dos 30-34 anos que possui um diploma do ensino superior. 5. Pobreza e exclusão social: reduzir, pelo menos, em 20 milhões o número de pessoas em risco ou em situação de pobreza ou de exclusão social". Disponível em: http:// ec.europa.eu/social/main.jsp?catId=101\&langId=pt . Acesso em 20 de abril de 2012. 
ganização do trabalho, pelo incremento da globalização da economia e o respectivo surgimento de economias emergentes mais competitivas (as asiáticas, por exemplo), e, no que se refere ao âmbito do trabalho, o aumento da imigração em solo Europeu e a configuração de um Estado de bem-estar social que não consegue dar respostas adequadas a estas temáticas. Em consequência, surge a defesa da ideia de flexibilizar o mercado de trabalho, através da chamada desregulamentação, tornando-o, desta forma, mais adaptável aos referidos novos contextos.

Considerando que o mercado de trabalho não é homogêneo, mas segmentado em vários critérios, tais como, a idade, o sexo, a nacionalidade, as qualificações das trabalhadoras e dos trabalhadores e, também, as exigências específicas de mercado, pode-se dizer que existem muitas e variadas formas de flexibilização. E se a erosão da relação convencional de trabalho é algo palpável e visível, natural que a flexibilidade se vincule às formas não convencionais de trabalho ou ditas atípicas, mas que não podem, ou melhor, não devem ser necessariamente formas precárias de emprego. A flexibilização pode ser associada, por exemplo, ao tempo de trabalho tipificado, entre outros, no trabalho descontinuo e no trabalho a tempo parcial que em âmbito Europeu estão delimitados por uma série de prerrogativas de proteção social. Seja neste ou em outros exemplos, o conceito de flexibilização passa a adquirir uma nova configuração e perspectiva legal: a flexycurity (flexisegurança).

A projeção do paradigma da flexycurity (flexisegurança) surgida na Dinamarca e nos Países Baixos na década dos anos 90 tem seus reflexos em âmbito Europeu a partir do Tratado de Amsterdam e, em particular, da publicação em 22 de novembro de 2006, do Livro Verde da Comissão Europeia intitulado "Modernizar o Direito ao trabalho para afrontar os objetivos do Século XXI" que a adota em matéria de política de emprego. finida como

Segundo Klammer and Tillmann (2001b, p. 16), a flexycurity pode ser de-

a policy strategy that attempts, synchronically and in a coordinated way, to enhance the exibility of labour markets, the work organization and labour relations on the one hand, and to enhance security | employment security and social security | notably for weak groups in and outside the labour market on the other hand (Apud TANGIAN, 2004, p.12).

Não obstante Tangian considere relevante a definição de Klammer e Tillmann, ele entende que a "Flexicurity is the employment and social security of atypically employed, that is, other than permanent full-time" (TANGIAN, 2004, p.12). Por sua vez, Ton Wilthagen entende que a

Flexicurity is (1) a degree of job, employment, income and combination security that facilitates the labour market careers and biographies of work- 
ers with a relatively week position and allows for enduring and high quality labour market participation and social inclusion, while at the same time providing (2) a degree of numerical (both external an internal), functional and wage flexibility that allows for labour markets' (and individual companies') timely and adequate adjustment to changing conditions in order to maintain and enhance competitiveness and productivity (WILTHAGEN, p. 6)

A flexycurity no trabalho pretende dar ensejo a um verdadeiro equilíbrio entre a flexibilidade e a segurança nas relações de trabalho. O paradigma Europeu de flexisegurança pretende superar, portanto, a oposição tradicional entre flexibilidade e segurança no mercado de trabalho a partir de uma nova lógica de convergência e complementaridade de ambos os conceitos. A flexisegurança combina as necessárias margens de gestão empresarial flexível de trabalho com a segurança da e do trabalhador a e do trabalhador no emprego, condicionantes que somente se alcançam com a cooperação necessária do sistema público de proteção social. Como atestam os documentos de referência Europeus aludidos no decorrer deste paper, a flexisegurança requer: i) um mercado de trabalho com disposições contratuais flexíveis e confiáveis; ii) instrumentos de flexibilidade interna na empresa; iii) estratégias de formação permanente; iv) políticas ativas e eficazes de emprego, bem como sistemas desenvolvidos de proteção social do desemprego sustentados por uma adequada distribuição dos custos públicos e privados. Com base nestas coordenadas, as estratégias de flexisegurança europeias destinam-se à redução da segmentação do trabalho entre as trabalhadoras e os trabalhadores permanentes e as trabalhadoras e os trabalhadores temporários, assim como a consecução de transições rápidas entre empregos com um claro compromisso com a formação e adaptação da e trabalhadora e trabalhador e a respectiva maximização da conciliação familiar com custos efetivamente redistribuídos entre o sistema público e o privado. Em definitivo, todas estas estratégias têm como objetivo final mais e melhores empregos, coesão social e adaptabilidade do mercado de trabalho à economia globalizada.

Em distintos instrumentos normativos a União Europeia tem expressado, desde a década passada, a sua intenção de crescimento. Os Chefes de Estado e de Governo da União Europeia reunidos no Conselho Europeu de Lisboa em Março de 2000, comprometeram-se a criar até 2010 "a economia baseada no conhecimento mais competitiva e dinâmica do mundo" (KOK, 2004, p. 48).

Para alcançar tal desígnio, adotaram uma vasta gama de técnicas, desde a legislação europeia normal até medidas inovadoras como a análise comparativa e a avaliação, pelos pares, das efetivas prestações levadas a bom termo pelos Estados-Membros. Este processo de reforma econômica teve como objetivo precípuo aumentar a competitividade na UE através de reformas e melhorias dos mercados de trabalho e o respectivo reforço da coesão social com vistas a garantir a compati- 
bilidade entre as novas políticas econômicas e ambientais. Para tanto foi criado um programa de trabalho de amplo alcance e calcado nos seguintes objetivos:

- Realização plena do mercado interno em setores-chave como as telecomunicações, a energia e os serviços financeiros;

- Aumento do acesso às novas tecnologias, incluindo os telefones móveis e o acesso à Internet;

- Fomento da investigação, através do aumento da despesa em investigação e desenvolvimento até 3\% do PIB e da adoção de um regime único Europeu de patentes;

- Aumento da concorrência nos transportes ferroviários e aéreos;

- Resolução dos problemas comuns das pequenas empresas e das empresas nascentes, fundamentais para a expansão do emprego;

- Promoção de mercados competitivos e redução dos subsídios à indústria que distorcem as condições de concorrência;

- Aumento da taxa de emprego geral para $70 \%$, bem como aumento da participação das mulheres e dos trabalhadores mais velhos;

- Valorização das qualificações dos trabalhadores e promoção de uma cultura de aprendizagem ao longo da vida;

- Exame cuidadoso dos regimes de pensões de forma a assegurar a sustentabilidade em longo prazo das finanças públicas;

- Modernização da proteção social, incluindo a redução do número de pessoas em risco de exclusão social;

- Abordagem das causas das alterações climáticas, mediante a redução das emissões de gases com efeito de estufa (KOK, 2004, p. 48).

A Comissão Europeia criou, então, um grupo de expertos em flexisegurança os quais publicaram, ainda em 2007, o Relatório Pathways to flexicurity ${ }^{195}$. No citado documento se define a flexisegurança como uma estratégia integrada para potencializar, ao mesmo tempo, a flexibilidade e a segurança no mercado de trabalho. De acordo com tal Relatório, também se entende por flexisegurança as transações ao longo da vida laboral, isto é, o acesso ao emprego desde o final da etapa educativa, de um emprego a outro, das transações dos trabalhadores para melhores empregos (mobilidade ascendente), do desemprego a inatividade ao trabalho e, por fim, do trabalho a aposentadoria. Esclarece-se, igualmente, que a flexisegurança não se limita a maior liberdade das empresas para contratar ou despedir e não implica, tão pouco, que os contratos por tempo indeterminado sejam figuras obsoletas. Quanto à segurança especificamente, não somente se menciona o fato de que a criação e conservação dos postos de trabalho é um objetivo a ser alcançado, mas também que exista segurança nas redes de transação de empregos. Isto se conseguirá, segundo o

195 Disponível em: https://infoeuropa.eurocid.pt/registo/000039764/. Acessado em: 20.04.2012. 
Relatório, através de uma melhora das capacidades das trabalhadoras e dos trabalhadores, mediante a formação - especialmente para as e os menos qualificadas e qualificados ou os que possuem mais idade - e ajudas para que as eos trabalhadoras e trabalhadores encontrem um novo posto de trabalho. Ademais, estes requisitos se completam com as prestações de desemprego adequadas a facilitar tais transações. Em resposta e apoio a esta iniciativa da Comissão Europeia, a Organização que agrupa as Agencias Privadas de Emprego a nível Europeu (EuroCiett ${ }^{196}$ ), junto com a Confederação de Sindicatos Europeus (UNI-Europa ${ }^{197}$ ), realizaram em 28 de fevereiro de 2007 uma declaração conjunta que buscava ser também mais um aporte em termos de flexisegurança. Em concreto tais organizações defendiam que deveriam se revisar as restrições ou proibições no que concerne ao uso, pelas empresas de trabalho temporário, deste tipo de contratação e suprimir aquelas que não estivessem devidamente justificadas. Apoiavam, igualmente, as diversas contribuições destas empresas ao mercado laboral, em geral, e a flexisegurança, em particular, como pontes entre o emprego e o desemprego.

De acordo com a Rede Europeia dos Diretores dos Serviços Públicos de Emprego (SPE) ${ }^{198}$, em sua vigésima terceira reunião a nível Europeu, celebrada em Nice em 11 de dezembro de 2008, muitas são as razões pelas quais entendem ser profícuo e viável a flexisegurança laboral. Não obstante, afirma dita Rede ser indispensável à participação do SPE dado sua inequívoca contribuição a inclusão social através do mercado de trabalho dos grupos sociais menos favorecidos. Portanto, e de acordo com o SPE, uma colaboração eficiente entre todos os agentes sejam eles governamentais ou não governamentais é indispensável para que se gerem programas efetivos de acesso e/ou retorno ao emprego.

Durante a $8^{a}$ Reunião Regional Europeia da OIT, realizada em fevereiro de 2009 em Lisboa, objetivou-se, através da integração da Agenda da Organização para o Ttrabalho Descente ${ }^{199}$, encontrar respostas possíveis em matéria de políticas

196 Disponível em: http://www.eurociett.eu/. Acesso em 20 de abril de 2012. Segundo Annemarie Muntz, presidenta do Eurociett: "There is a clear role for labour market intermediaries such as private employment services in implementing many elements of the Package - including meeting the skills shortages in growth areas such as ICT and Healthcare. The greater challenge for governments going forward will be to implement flexicure labour reforms and to ensure that social security systems and portability of rights are in place to meet the new reality of work."

197 Disponível em: http://www.uniglobalunion.org/Apps/uni.nsf/pages/reg_europaEn. Acessado em: 20.04.2012.

198 Disponível em: http://ec.europa.eu/eures/main.jsp?catId=29\&acro=eures\&lang=pt. Acessado em: 28.04.2012.

199 Segundo dita Agenda, “Atualmente, o principal objetivo da OIT consiste em promover oportunidades para que mulheres e homens possam ter acesso a um trabalho digno e produtivo, em condições de liberdade, equidade, segurança e dignidade". Veja-se mais em OIT. Decent work, Report of the Director-General. Conferência Internacional da OIT, $87^{\text {a }}$ Sessão, 
sociais e de emprego com vistas a afrontar à crise econômica e financeira e às respectivas perdas de empregos. Segundo Juan Somavia, Diretor-Geral da OIT,

Assistimos a uma degradação alarmante dos níveis de produção e de emprego na região com [...] repercussões sociais e políticas de uma recessão profunda e duradoura [...]. A nossa atenção deve incidir prioritariamente nos meios de impedir que se deslize para uma recessão social generalizada (SOMAVIA, 2008, p. 1).

Corrobora a afirmação de Somavia o estudo da OIT realizado no período compreendido entre 2004-2010 sobre a Tendência Mundial do Emprego (Global Employment Trends $^{200}$ ) que demonstrou a retração do crescimento à época e a previsão de piores índices para 2009, bem como a necessidade premente de implantar novas políticas de enfrentamento da questão, pois o adiamento de tais políticas acarretaria para a região do Sudeste da Europa (aquela que inclui os países não-membros da União Europeia) e da Comunidade de Estados Independentes (CEI) uma elevação da taxa de desemprego de 8,8\%, em 2008, para 9,8\%, em 2009, enquanto na União Europeia e nas outras economias desenvolvidas, a taxa de desemprego poderia aumentar um ponto percentual, passando de 6,4\%, em 2008, para 7,9\%, em $2009^{201}$. Dita Reunião Regional lançou, ademais, uma nota pública sobre flexisegurança na que se menciona o "equilíbrio sensato" entre ambos os conceitos. Reafirmando também a ideia de adaptar o modelo de flexisegurança segundo a singularidade de cada país e, sobretudo que, "a flexisegurança necessita, e também promove, taxas de emprego mais altas". O documento ainda destaca algumas normas chaves da OIT relacionadas com a flexigurança entre as que se encontram a Convenção n. ${ }^{\circ} 181$ sobre as Agências Privadas de Emprego de 19 de junho de 1997 (ratificada pela Espanha em 15 de junho de 1999) a na qual se define o conceito de Agências Privadas de Emprego, assim como as atividades que por elas podem ser desenvolvidas ${ }^{202}$.

Genebra, 1999. Disponível em: http://www.ilo.org/public/english/standards/relm/ilc/ilc87/ rep-i.htm. Acessado em: 01.05.2012.

200 Disponível em: http://www.ilo.org/wcmsp5/groups/public/@dgreports/@dcomm/@ publ/documents/publication/wcms_171571.pdf . Acessado em: 01.04.2012.

201 Cabe lembrar que as taxas de desemprego em 2013 são em países como Espanha, Portugal e Grécia muito piores que as apontadas pelo estudo em tela. Em março/2013 a taxa de desemprego na Grécia foi de $26,80 \%$ e os dados de julho/2013 apontam que $17,60 \%$ da população ativa de Portugal se encontra desempregada. Neste mesmo período (julho/2013) na Espanha o desemprego alcançou o percentual de 27, 16\% da população ativa, atingindo a 6.202 .700 pessoas.

202 Artigo $1^{\circ}$ da Convenção n. ${ }^{\circ} 181.1$ - Para os efeitos da presente Convenção, a expressão «agência de emprego privada» designa qualquer pessoa singular ou coletiva, independente das autoridades públicas, que preste um ou mais dos seguintes serviços referentes ao mercado de trabalho:a) Serviços que visam a aproximação entre ofertas e procuras de emprego, sem 
Além das instituições mencionadas e suas respectivas normativas, outros expertos se dedicaram a analisar os impactos da flexisegurança laboral e, entre eles, Andranik Tangian ${ }^{203}$, que no período de 2004 a 2008 publicou pelo menos quatro artigos sobre este tema elaborando um índice de flexisegurança para os países Europeus a partir das pesquisas efetuadas pela Organização de Cooperação e Desenvolvimento Econômico - $\operatorname{OCDE}^{204}$ (1999-2002) e da definição cunhada por Wilthagen e Tros ${ }^{205}$ para a flexisegurança laboral, passando a conceituá-la como "[...] is the employment and social security of atipically employed, that is, other than permanent full-time" (ANDRANIK, 2004, p. 12). A partir deste conceito, Tangian elabora um modelo de dados de painel onde compara dezesseis países por um período de quatorze anos analisando critérios jurídicos de flexisegurança (modelos: nórdico, anglo-saxão, continental e mediterrâneo) e oito categorias de emprego agrupadas em três grandes tipos e níveis de segurança (normal security, flexicurity y all-security).

As análises de Tangian realizadas posteriormente (2008) desvendam que a aplicação da flexisegurança não indicou, conforme previa a Comissão Europeia, a mencionada certeza de ampliação dos índices de emprego.

Daí que sua proposta consistirá na implantação de alguns itens, a saber: 1) em um seguro por desemprego; 2) em contribuições a previdência social mais

que a agência de emprego privada se torne parte nas relações de trabalho que daí possam decorrer;b) Serviços que consistem em empregar trabalhadores com o fim de os pôr à disposição de uma terceira pessoa, singular ou coletiva (adiante designada «empresa utilizadora»), que determina as suas tarefas e supervisiona a sua execução;c) Outros serviços relacionados com a procura de empregos que sejam determinados pela autoridade competente após consulta das organizações de empregadores e de trabalhadores mais representativas, tais como o fornecimento de informações, sem que no entanto visem aproximar uma oferta e uma procura de emprego específicas.2 - Para os efeitos da presente Convenção, a expressão «trabalhadores» abrange os candidatos a empregos. 3 - Para os efeitos da presente Convenção, a expressão «tratamento dos dados pessoais referentes aos trabalhadores » designa a recolha, a armazenagem, a combinação e a comunicação de dados pessoais ou qualquer outro uso que possa ser feito de qualquer informação que diga respeito a um trabalhador identificável. Disponível em: http://www.oitbrasil.org.br/content/conven $\% \mathrm{C} 3 \% \mathrm{~A} 7 \% \mathrm{C} 3 \% \mathrm{~A} 3 \mathrm{o}$-relativa- $\% \mathrm{C} 3 \% \mathrm{~A} 0$ s-ag\%C3\%AAncias-de-emprego-privadas. Acesso em 01 de maio de 2012.

203 TANGIAN, Andranik. (2008). On the European Readiness for Flexicutiry: Empirical Evidence with OECD / HBS Methodologies and Reform Proposals. WSI-Diskussionspapier Nr. 160. April 2008. Disponível em: http://www.boeckler.de/pdf/p_wsi_diskp_160_e.pdf. Acessado em: 20.04.2012. TANGIAN, Andranik. (2004). Defining the flexicurity index in application to European countries. Diskussionspapier Nr. 122. Disponível em: http://www. boeckler.de/pdf/p_wsi_diskp_122.pdf. Acesso em 20 de abril de 2012.

204 Fazem parte da OCDE 36 países. A Espanha é membro, mas o Brasil não.

205 WILTHAGEN, T. e TROS, F.H. The Concept of Flexicurity: A New Approach to Regulating Employment and Labour Markets. New York, Social Science Research Network SSNN, 2008. Disponível em: http://papers.ssrn.com/sol3/papers.cfm?abstract_id=1133932. Acessado em: 27.04.2012. 
elevadas e proporcionais à flexibilidade do contrato, semelhante ao que ocorre nos sistemas austríaco e da experience rating dos Estados Unidos; 3) inclusão de uma workplace tax, ou seja, um imposto sobre as empresas que oferecem trabalho em más condições ou abaixo do standar usual de cada Estado; 4) criação de um imposto ecológico para a proteção do meio ambiente.

De acordo com esta proposta, uma parte destes impostos deverá ser paga a trabalhadora e o trabalhador como um bônus pelas 'más' condições de contrato e outra parte, por sua vez, ao Estado como ente supervisor.

Neste mesmo sentido se inclina a União Europeia ao afirmar que a melhor ferramenta para se lutar contra a exclusão social consiste em proporcionar as eos cidadãs e cidadãos um trabalho remunerado que lhes permitirá a integração sócio -econômica. Precisamente por isto, enfatiza Maria Luisa Hernández a necessidade que se fortaleçam os sistemas de proteção social - Previdência e Assistência Sociais - dos Estados-membros de forma tal que não obstaculizem as novas formas de trabalho atípicas que apareceram ao longo das últimas décadas e, entre elas, o trabalho a tempo parcial que "por seu caráter flexível contribui - ou pode contribuir - de forma significativa ao crescimento do emprego, e de maneira derivada, a luta contra a exclusão social" (HERNÁNDEZ, 2008, p. 160). Analisar-se-á nas próximas seções como as relações de trabalho a tempo parcial serão normatizadas nos ordenamentos internacional, comunitário e Espanhol.

\section{A proteção social das trabalhadoras e dos trabalhadores a tempo PARCIAL NOS ORDENAMENTOS INTERNACIONAL E COMUNITÁRIO}

Tal como se abordou até o momento, a proteção social das trabalhadoras e dos trabalhadores a tempo parcial é objeto de regulamentação especifica tanto pela OIT como pela União Europeia.

\section{1. Normas de CARÁter INTERNACIONAL}

A Convenção n. ${ }^{\circ} 175$ sobre Trabalho a Tempo Parcial e a Recomendação n. ${ }^{\circ} 182$ que a desenvolve, ambas normativas da OIT, reconhecem a pertinência para as eos trabalhadoras e trabalhadores a tempo parcial das seguintes disposições: 1) Convenção sobre a Igualdade de Remuneração de 1951, da Convenção sobre a Discriminação (emprego e profissão) de 1958; 2) Convenção e da Recomendação sobre os Trabalhadores com Responsabilidades Familiares de 1981; 3) Convenção sobre a Promoção do Emprego e a Proteção contra o Desemprego de 1988; e, da, 4) Recomendação sobre a Política de Emprego (disposições complementares) de 1984. Enfatiza-se, em definitivo, na Convenção n. ${ }^{\circ} 175$ a

[...] importância que reveste para o conjunto dos trabalhadores um empre- 
go produtivo e livremente escolhido, a importância do trabalho a tempo parcial para a economia, a necessidade de as políticas de emprego tomar em consideração o papel desempenhado pelo trabalho a tempo parcial na criação de possibilidades suplementares de emprego e a necessidade de assegurar a proteção dos trabalhadores a tempo parcial nos domínios do acesso ao emprego, das condições de trabalho e da previdência e assistência sociais.

Instituindo, no Artigo $1 .^{\circ}$, que

a) A expressão «trabalhador a tempo parcial» designa um trabalhador assalariado cuja duração normal do trabalho é inferior à dos trabalhadores a tempo completo e que se encontram numa situação comparável;

b) A duração normal do trabalho visada na alínea a) pode ser calculada numa base semanal ou em média no decurso de um dado período de emprego;

c) A expressão «trabalhador a tempo completo que se encontre numa situação comparável» refere-se a um trabalhador a tempo completo:

i) Que tenha o mesmo tipo de relação de emprego;

ii) Que efetue o mesmo tipo de trabalho, ou um tipo de trabalho similar, ou que exerça o mesmo tipo de profissão, ou um tipo de profissão similar; e iii) Empregado no mesmo estabelecimento ou, na falta de trabalhadores a tempo completo que se encontrem numa situação comparável nesse estabelecimento, na mesma empresa ou, na falta de trabalhadores a tempo completo que se encontrem numa situação comparável nessa empresa; no mesmo ramo de atividade do que o trabalhador a tempo parcial visado;

d) Os trabalhadores a tempo completo em desemprego parcial, isto é, afetados por uma redução coletiva e temporária da sua duração normal do trabalho por razões econômicas, técnicas ou estruturais, não são considerados trabalhadores a tempo parcial (OIT, 1994, p. 1.).

Se bem que a Convenção n. ${ }^{\circ} 175$ da OIT (art. $6^{0206}$ ) procura garantir as trabalhadoras e os trabalhadores a tempo parcial uma igualdade de trato com relação às trabalhadoras e os trabalhadores a tempo completo que se encontram em situação

206 Artigo 6. ${ }^{\circ}$ da Convenção 175 da OIT: “Os regimes legais de segurança social que estejam ligados ao exercício de uma actividade profissional devem ser adaptados de modo que os trabalhadores a tempo parcial beneficiem de condições equivalentes às dos trabalhadores a tempo completo que se encontrem numa situação comparável; essas condições poderão ser determinadas proporcionalmente à duração do trabalho, às quotizações ou aos ganhos, ou por outros métodos conformes com a legislação e a prática nacionais". OIT. Convenção $n .^{\circ} 175$, sobre Trabalho a Tempo Parcial. Genebra, 1994, p. 1. Disponível em: http:/www.gddc.pt/ siii/docs/rar37-2006.pdf Acesso em 01 de maio de 2012. 
comparável, acaba, por outro lado, em seu art. $8^{0207}$, por excluir garantias no que tange às prestações da Previdência Social, exceto no que diz respeito a prestações de acidentes de trabalho, de doenças profissionais e das medidas de proteção da maternidade que não as previstas por regimes legais de segurança social.

A Recomendação n. ${ }^{\circ} 182$ da OIT, retomando a importância deste tipo de trabalho para o crescimento das taxas de emprego e da economia, ressalta, ademais, a imperiosa necessidade de que a sua configuração não seja mais um desincentivo ao recurso ao trabalho a tempo parcial ou a aceitação de trabalhos desta índole. Estabelecendo, por conseguinte, a exigência de que em todo caso os regimes de Previdência e Assistencia Sociais devam ser configurados em cada Estado como instrumentos ao serviço de sua política de emprego e da respectiva flexibilização com segurança das relações de trabalho.

\section{2. NORMAS de CARÁTER COMUNITÁRIO}

- Diretiva 97/81/CE do Conselho da União Européia de 15 de dezembro de 1997 respeito ao Acordo-quadro relativo ao trabalho a tempo parcial celebrado pela União Europeia das Empresas e dos Emprendedores(UNICE), pela União Europeia do Artesanato e das Pequenas e Médias Empresas (CEEP) e pelo Centro Europeu das Empresas e da Participação Pública(CES $)^{208}$. Dito Acordo-quadro/marco constitui um contributo para a estratégia geral europeia em matéria de emprego. Não obstante, reconhecendo tanto a diversidade das situações encontradas nos Estados-membros, como o fato de o trabalho a tempo parcial ser um elemento característico do emprego em alguns setores e atividades, dito Acordo-quadro/marco define os princípios gerais e prescrições mínimas em matéria de trabalho a tempo parcial ilustrando a vontade dos parceiros sociais em relação ao estabelecimento de um quadro geral para a eliminação da discriminação contra as trabalhadoras e os trabalhadores a tempo parcial. Ademais, a Diretiva 97/81/CE estabelece que compete aos Estados-membros deliberarem sobre as questões relativas à Previdência e Assistência Sociais.

207 Artigo $8 .^{\circ} 1$ - Os trabalhadores a tempo parcial cuja duração do trabalho ou os ganhos sejam inferiores a determinados limites poderão ser excluídos por um membro: a) Do âmbito de aplicação de qualquer dos regimes legais de segurança social visados no artigo $6 .^{\circ}$, salvo se se tratar das prestações de acidentes de trabalho e de doenças profissionais; b) Do âmbito de aplicação de qualquer das medidas adotadas nos domínios visados no artigo $7 .^{\circ}$, com exceção das medidas de proteção da maternidade que não as previstas por regimes legais de segurança social. OIT. Convenção n. ${ }^{\circ} 175$, sobre Trabalho a Tempo Parcial. Genebra, 1994, p. 1. Disponível em: http://www.gddc.pt/siii/docs/rar37-2006.pdf .Acessado em: 01.05.2012. 208 Disponível em: http://eur-lex.europa.eu/LexUriServ/LexUriServ.do?uri=CELEX:31997L0081:PT:HTML. Acessado em: 02.05.2012. 
- Diretiva 1999/70/CE do Conselho da União Européia de 28 de junho de 1999 respeito ao acordo-quadro CES, UNICE e CEEP relativo a contratos de trabalho a termo. O presente acordo-quadro ilustra o papel que os parceiros sociais podem desempenhar na estratégia europeia para o emprego acordada na Cimeira extraordinária realizada em 1997 em Luxemburgo. Representa uma contribuição adicional para a consecução de um maior equilíbrio entre a "flexibilidade do tempo de trabalho e a segurança dos trabalhadores". O presente acordo estabelece os princípios gerais e os requisitos mínimos relativos aos contratos de trabalho a termo, reconhecendo que a sua aplicação pormenorizada deve ter em conta a realidade e especificidades das situações nacionais, setoriais e sazonais. Afirma ainda a vontade dos parceiros sociais em estabelecerem um quadro-geral que garanta a igualdade de tratamento em relação as trabalhadoras e os trabalhadores contratados a termo, protegendo-lhes contra as discriminações e a não utilização deste tipo de contrato sem que se proponha e garanta uma base aceitável tanto para empregadores como para as trabalhadoras e os trabalhadores . Cabe ressaltar que a Diretiva 1999/70/CE é aplicável as trabalhadoras e os trabalhadores contratados a termo com exceção daqueles que são colocados por uma empresa de trabalho temporário à disposição de uma empresa utilizadora de seus serviços. Assim como a Diretiva 97/81/ $\mathrm{CE}$, o presente acordo deixa a cargo dos Estados a competência para deliberarem sobre as questões relativas à Previdência e Assistência Sociais, ressaltando, não obstante, a importância de se levar em consideração a declaração sobre o emprego do Conselho Europeu de Dublim de 1996 e que destaca, entre outras prerrogativas, a necessidade de desenvolver os sistemas de Previdência e Assistência Sociais mais favoráveis ao emprego desenvolvendo sistemas de proteção social capazes de se adaptarem aos novos modelos de trabalho e de proporcionar uma proteção adequada a todas e todos aquelas e aqueles que efetuam este tipo de trabalho.

A Diretiva 1999/70/CE estabelece também disposições para evitar os abusos previstos no art. $5 .^{\circ}$, in verbis:

1. Para evitar os abusos decorrentes da conclusão de sucessivos contratos de trabalho ou relações laborais a termo e sempre que não existam medidas legais equivalentes para a sua prevenção, os Estados-Membros, após consulta dos parceiros sociais e de acordo com a lei, acordos coletivos ou práticas nacionais, e/ou os parceiros sociais deverão introduzir, de forma a que se tenha em conta as necessidades de setores e/ou categorias de trabalhadores específicos, uma ou várias das seguintes medidas:

a) Razões objetivas que justifiquem a renovação dos supramencionados 
contratos ou relações laborais;

b) Duração máxima total dos sucessivos contratos de trabalho ou relações laborais a termo;

c) Número máximo de renovações dos contratos ou relações laborais a termo.

2. Os Estados-Membros, após consulta dos parceiros sociais, e/ou os parceiros sociais, deverão, sempre que tal seja necessário, definirem que condições os contratos de trabalho ou relações de trabalho a termo deverão ser considerados:

a) Como sucessivos;

b) Como celebrados sem termo.

Informação e possibilidades de emprego (artigo $6^{\circ}$ )

1. Os empregadores deverão informar os trabalhadores contratados a termo sobre as vagas disponíveis na empresa ou no estabelecimento para garantir que tenham as mesmas oportunidades que outros trabalhadores de aceder a postos de trabalho permanentes. Esta informação poderá ser prestada através de anúncio geral afixado no local adequado da empresa ou do estabelecimento.

2. Na medida do possível, os empregadores deverão facilitar o acesso dos trabalhadores contratados a termo às oportunidades de formação adequadas com vista ao aumento das suas competências, do progresso na sua carreira e à mobilidade profissional.

Cabe analisar na próxima seção como a Espanha articulou-se para modernizar o mercado de trabalho cingindo-se as leis trabalhistas e de proteção social com vistas a promover o crescimento interno e a coesão sócio-econômica.

\section{A PROTEÇÃo SOCIAL DOS TRABALHADORES A TEMPO PARCIAL NO ORDENAMEN- TO ESPANHOL}

A projeção do paradigma da flexisegurança também acaba sendo adotada em matéria de política de emprego pelo Estado Espanhol. Segundo os resultados tornados públicos pelo Banco de España na obra "La Flexiseguridad como modelo para los mercados de trabajo europeos", o IFX (Core Flexicurity Indicator), indicador de flexisegurança europeia aplicado nas comunidades autônomas espanholas no período datado entre 2005 - 2008, revelaram-se significativos avanços na implantação da flexigurança naquele país ${ }^{209}$. Dito informe estabelece, seguindo outros modelos, um

209 BANCO DE ESPAÑA, 2007. Estudos similares também foram realizados pela AGETT (Asociación de Grandes Empresas de Trabajo Temporal) e a CEPREDE (Centro de Predicción Económica no que concerne ao IFX) o IFX (Core Flexicurity Indicator). Veja-se em AGETT e CEPREDE. Flexiseguridad laboral en España. Madrid: 2009. Disponível 
conjunto de oito indicadores aplicados em âmbito Europeu em nível de países e, na pesquisa em tela, para as comunidades autônomas espanholas no período contemplado entre 1980-2003. Utilizaram-se como parâmetros os quatro modelos de flexisegurança europeia (nórdico, anglo-saxão, continental e mediterrâneo). Tais indicadores são: a proteção por desemprego, as prestações por desemprego, as políticas ativas de emprego, a formação continuada, a regulação do mercado de produtos, a regulamentação sobre o trabalho, o nível de sindicalização e a coordenação da negociação coletiva. Como o índice de flexisegurança se constitui como benchmarking respeito à Dinamarca, o IFX mede a distância em termos de flexisegurança (desvios) com respeito a esta referência danesa. O mercado de trabalho Espanhol apresenta cinco parâmetros contrários às denominadas estratégias europeias de flexisegurança, a saber: 1) alta segmentação entre o trabalho permanente e o trabalho temporário; 2) deficiências de empregabilidade, bem como poucas e lentas transições entre postos de trabalho; 3 ) escassa flexibilidade interna nas empresas; 4) a inexpressiva conciliação da vida familiar e laboral; e, 5) a exígua eficiência na redistribuição dos custos privados e públicos dirigida menos a garantir um equilíbrio entre a flexibilidade e a segurança e mais em amortecer a perda de emprego.

A crise atual da economia espanhola demonstrou, segundo o mencionado levantamento, a necessidade de se estabelecer naquele país um modelo de flexisegurança laboral que reduza a dualidade de trabalho, potencialize a flexibilidade interna, aposte na formação e na adaptabilidade das trabalhadoras e dos trabalhadores facilitando desta forma as transições rápidas entre empregos e a consequente necessidade de instauração de uma sólida proteção social e uma eficaz e eficiente redistribuição dos custos públicos e privados com vistas a alcançar estes objetivos. Dentro deste quadro de análise pode-se argumentar que as reformas do mercado de trabalho instituídas pelo Governo Espanhol - Ley 35/2010, após amplo acordo social, bem como os Decretos-Leyes 1/2011 e 3/2011 - tiveram como objetivo introduzir uma maior flexisegurança laboral na Espanha (ainda que, tal qual se comentará nas ponderações finais, tão pouco ditas reformas alcançaram seus objetivos, posto que sofreram recentemente novas reformulações dispostas no Real Decreto-Ley 3/2012).

As reformas trabalhistas de 2010-2011 possuíam, como denominador comum, a flexisegurança laboral europeia. Mas o caminho adotado pelo mercado de trabalho Espanhol parece continuar exigindo, ademais da adaptação aos padrões Europeus, as necessárias alterações no modelo de produção daquele país, processo que se entende deve ser desenvolvido em longo prazo e que exige, igualmente, a persistência nos objetivos propostos, bem como o contínuo e eficiente investimento público e a consciência cidadã de que uma mudança de paradigma nas relações laborais dever ter como base, segundo a União Europeia, a flexisegurança.

Em se tratando do caso Espanhol, a Organização para a Cooperação e De-

em: http://www.agett.com/servicio/informes/Flexiseguridad\%20laboral\%20en\%20Espa\%F1a\%202009.pdf. Acesso em: 30.04.2012. 
senvolvimento Econômico - OCDE em seu relatório España debe hacer más para los jóvenes y el trabajo (2007) ${ }^{210}$ oferece várias recomendações para melhorar a situação do mercado de trabalho dos jovens, sendo as mais relevantes: assegurar a disponibilidade de aprendizagem nas empresas para todas e todos as e os estudantes de formação profissional; alcançar uma maior convergência no tratamento dos contratos temporários em relação com os indefinidos; incrementar a duração do período de estágio probatório nos contratos indeterminados; e assegurar que se ofereçam de forma mais eficaz serviços de emprego aos jovens desempregados.

Cabe analisar ainda qual é o regime de proteção social atualmente aplicável as trabalhadoras e os trabalhadores a tempo parcial na Espanha. Não se exporá, seguindo a Hernández Martín, o regime jurídico-positivo de cada um dos benefícios sociais que o sistema Espanhol de proteção social reconhece para este tipo de trabalho atípico, mas simplesmente se mostrarão quais são os traços que caracterizam a proteção social para, a continuação, chegar a uma conclusão sobre em que medida tal regime se encaixa ou não nas exigências que, a respeito, advêm da própria União Europeia, concretamente aquelas relacionadas com a flexisegurança. Trata-se, portanto, de determinar, em que medida, aquele sistema de proteção social está adaptado às peculiaridades do trabalho parcial e permite alcançar os três principais objetivos

210 El informe, "Empleos para los jóvenes: España", destaca que: "la tasa de paro juvenil, que alcanza casi el $18 \%$ en 2006, todavía supera en más de tres puntos porcentuales la media de la OCDE. En particular, las mujeres jóvenes españolas tienen una de las tasas de paro más elevadas en la OCDE. Y, aunque la incidencia del trabajo temporal entre los jóvenes ocupados tiende a descender, todavía se sitúa en el $66 \%$ en 2006, más del doble de la media de la OCDE, próxima al 30\%. Como en otros países de la OCDE, muchos jóvenes entran en el mercado de trabajo con un contrato temporal. Sin embargo, España es el único en el que el joven tiende a permanecer con contratos temporales durante un largo período de tiempo, intercalando períodos frecuentes de paro cuando se mueven de un contrato a otro hacia el próximo empleo. Es necesario eliminar numerosas barreras para mejorar las perspectivas del mercado de trabajo de los jóvenes en España. En primer lugar, como en otros países de la OCDE, el mercado de trabajo es cada vez más selectivo y la carencia de calificaciones relevantes constituye un riesgo más alto de paro. En España, uno de cada cuatro jóvenes abandona los estudios con un nivel inferior a la educación secundaria superior, una de las tasas de abandono escolar más elevadas entre los países de la OCDE. Además, los vínculos entre el sistema educativo y el trabajo son demasiado débiles y el aprendizaje basado en el trabajo se limita a los estudiantes de formación profesional, cuyos resultados en términos de acceso al empleo después de dejar la escuela son relativamente buenos. En segundo lugar, los progresos se han visto obstaculizados por el hecho de que la relativa rigidez de la protección del empleo para los contratos indefinidos ha contribuido a la segmentación del mercado de trabajo entre empleos temporales y permanentes característica del mercado de trabajo español, lo cual afecta negativamente a las perspectivas de carrera profesional y a las oportunidades de formación de los jóvenes. En tercer lugar, se deben hacer mayores esfuerzos para ayudar a los jóvenes desempleados, en particular a los más desaventajados, a encontrar un empleo". Disponível em: http://www.oecd.org/document/14/0,3746, en_21571361_44315115_38545038_1_1_1_1,00.html. Acesso em: 24.04.2012. 
definidos pelas instituições comunitárias à respeito: garantir as eos trabalhadoras e trabalhadores que o desempenham o acesso à prestações suficientes e adequadas frente as diversas situações de risco social e nas quais possam encontrar um novo contexto sócio-econômico, de modo que, em todo o caso, se consiga evitar o risco de exclusão social das e dos mesmos; incentivar o recurso ao trabalho a tempo parcial tornando-o mais atrativo; e, por fim, favorecer as mudanças das trabalhadoras e dos trabalhadores a tempo parcial para postos de trabalho de mais qualidade.

Para conhecer qual é o regime de proteção social que na atualidade se aplica as trabalhadoras e os trabalhadores a tempo parcial e poder extrair conclusões sobre em que medida contribui para dotar os mesmos de um nível viável de segurança e, portanto, constituí-lo em um emprego de qualidade, faz-se necessário analisar os seguintes aspectos de tal sistema: as regras sobre os períodos de contribuição exigidos; a forma de calcular as bases da contribuição e a ação protetora. Faz-se necessário utilizar também com fundamento na Disposição Adicional $7^{\mathrm{a}}$ do texto refundido da Lei Geral de Seguridade Social, aprovado pelo Real Decreto Legislativo 1/1994, em 20 de junho de 1994 (doravante, LGSS) e o Real Decreto 1131/2002, de 31 de outubro de 2002, pelo qual se regulamenta a Previdência Social das trabalhadoras e dos trabalhadores a tempo parcial.

Estas normas pretenderam adaptar o regime de proteção social das trabalhadoras e dos trabalhadores a tempo parcial à regulação substantiva vigente, resultado de sucessivas reformas - todas elas tendentes a flexibilizar a figura e a fomentar a sua maior utilização, dado que a considera um instrumento adequado para incrementar o emprego estável no âmbito Espanhol. O princípio, formalmente declarado na citada Disposição adicional da LGSS e que, portanto, inspira - ou deveria inspirar toda a normativa que desenvolve o regime de proteção social das trabalhadoras e dos trabalhadores a tempo parcial -, é o de "equiparação" deste tipo de trabalho ao trabalho a tempo completo. Imprescindível, agora, comprovar em que medida as regras que ordenam a proteção social das trabalhadoras e dos trabalhadores a tempo parcial respondem realmente a tal princípio.

Para que tais trabalhadoras e trabalhadores possam receber as prestações previdenciárias (por morte, por incapacidade temporária para o trabalho, por licença-maternidade e paternidade) é imprescindível que possuam um período mínimo de carência no sistema. Em outros termos, um período de contribuições previdenciárias mínimas. Dito período é calculado com base nas contribuições (quotizações) repassadas ao Sistema Previdenciário Espanhol com base nas horas efetivamente trabalhadas. Nesse cálculo de horas inclui-se tanto as horas ordinárias como as extraordinárias trabalhadas. De acordo com o Regime Espanhol, tais horas são denominadas de dias teóricos de quotização. Nos casos de pensão por aposentadoria e de incapacidade permanente para o trabalho, a regra anterior é complementada por outra adicional e que consiste na aplicação de um coeficiente multiplicador $(1,5)$ aos dias teóricos de quotização, obtidos conforme a regra anterior, desde que em nenhum 
caso os dias quotizados sejam superiores ao que corresponderia aos casos de prestação de serviços a tempo completo. Esta regra pretende facilitar as trabalhadoras e os trabalhadores a tempo parcial o acesso a ditas prestações que exigem períodos de carência mais longos.

Em matéria de desemprego não se utiliza o princípio de proporcionalidade, posto que se equipara o trabalho a tempo parcial ao trabalho por tempo completo no que concerne aos períodos de contribuição exigíveis para ter acesso a esse direito.

Nos casos em que a trabalhadora e o trabalhador realize simultaneamente mais de uma atividade a tempo parcial, somam-se as horas creditadas às distintas atividades, tanto nas situações de pluriemprego como nas de pluriatividade ${ }^{211}$, sempre que, com respeito a essas se aplique o cômputo recíproco de contribuições. Pelo contrário, se no acesso e/ou para a determinação da quantia das prestações não se efetua tal computo, não se somam as contribuições realizadas, devendo-se considerar, separadamente, as contribuições realizadas em cada um dos regimes de enquadramento.

Pode-se concluir, portanto, que a aplicação das regras previstas para as bases de contribuição (quotização) refletem no direito a percepção da prestação social a que farão jus as trabalhadoras e os trabalhadores a tempo parcial. Em outros termos, dita percepção está diretamente relacionada com o salário recebido e configurado pelas horas de trabalho realizadas no âmbito do trabalho a tempo parcial e as respectivas apurações feitas ao Sistema de Previdência Social a este respeito, o que equivale a afirmar que tais trabalhadoras e trabalhadores receberam benefícios previdenciários proporcionais. E, ainda que o Tribunal Constitucional Espanhol na sentença 253/de 22 de dezembro de 2004 tenha mencionado expressamente com base no Artigo 14 da Constituição Espanhola a imperiosidade do princípio de igualdade e não discriminação, persiste a existência de problemas no que concerne a suficiência das prestações, posto que efetivamente a pretendida regra da proporcionalidade não se aplica em sua real acepção.

211 Segundo o Sistema Previdenciário Espanhol se entende por pluriemprego "la situación del trabajador por cuenta ajena que preste sus servicios profesionales a dos o más empresarios distintos y en actividades que den lugar a su alta obligatoria en un mismo Régimen de la Seguridad Social. En este supuesto, para determinar el tope máximo a aplicar, se distribuirá el tope máximo establecido con carácter general entre todos los sujetos de la obligación de cotizar en proporción a las retribuciones abonadas en cada una de las empresas en que preste sus servicios el trabajador, sin que, respecto a las contingencias comunes, la fracción del tope máximo que se asigne a cada empresa o sujeto obligado pueda ser superior a la cuantía de la retribución abonada al trabajador. El tope mínimo se prorrateará asimismo entre todas las empresas y demás sujetos de la obligación de cotizar, en proporción a las retribuciones percibidas en cada una de ellas". Por pluriatividade se entende "la situación del trabajador por cuenta propia y/o ajena cuyas actividades den lugar a su alta obligatoria en dos o más Regímenes distintos del Sistema de la Seguridad Social". Disponível em: http://www.segsocial.es/Internet_1/Trabajadores/CotizacionRecaudaci10777/Areainformativa/Elementosdecotizaci11301/SupuestosEspeciales11331/index.htm. 


\section{Conclusão}

Segundo uma série de publicações da OIT referentes ao Pacto Mundial para o Emprego os regimes de tempo de trabalho reduzido ou parcial (também denominado de desemprego parcial ou técnico) representam um importante instrumento para limitar ou evitar as perdas de emprego e a respectiva solvência das empresas. Deduz-se, da leitura das páginas anteriores, que o trabalho a tempo parcial pretende ser também uma forma de distribuição de um menor volume de trabalho entre uma cifra igual, similar e/ou superior de trabalhadoras e trabalhadores com o fim de aumentar os postos de trabalho, conciliar a formação contínua das trabalhadoras e dos trabalhadores, bem como sua vida familiar com a laboral possibilitando, desta forma e, sobretudo, a empregabilidade, evitando, por conseguinte, o desemprego e a consequente exclusão social. Quando as políticas públicas deste tipo se formulam e executam de maneira adequada, como demonstram os dados de alguns países Europeus, tanto as trabalhadoras e os trabalhadores como também os empregadores e empresas $^{212}$ e, assim sendo, a sociedade em geral, tendem a ser beneficiados com a sua aplicabilidade.

Ainda que os dados finais sobre os efeitos dos programas de redução da jornada de trabalho ou de desemprego parcial desde o início da crise econômica que assola a Europa e, em particular, a Península Ibérica, sejam inconclusos, alguns estudos, entre eles o da OCDE intitulado Employment Outlook: Moving Beyond the Jobs crisis publicado em 2010, afirmando que as economias da OCDE estão enfrentando o desencorajador e duplo desafio de reduzir as elevadas taxas de desemprego e subemprego ao mesmo tempo que afrontam déficits fiscais sem precedentes (OCDE , 2010, p. 2), alega-se, não obstante, que os "resultados aportam provas de que os programas de desemprego parcial ajudaram a conservar postos de trabalho permanentes durante a recessão econômica, ademais de incrementar a redução media da jornada de trabalho dos trabalhadores permanentes" (OCDE , 2010, p. 68). O relatório da OCDE assevera também que os países que já possuíam regimes de trabalho a tempo parcial antes da crise conseguiram aproveitar suas vantagens para minimizar os efeitos da recessão sobre o mercado de trabalho através das modificações encaminhadas a ampliá-lo e adaptá-lo a situação atual.

Esta assertiva não parece ser possível de corroboração no caso Espanhol principalmente depois da promulgação, no passado dia 10 de fevereiro de 2012, do Real Decreto-Ley 3/2012 e das chamadas medidas urgentes para a reforma do mercado laboral. Em suas disposições gerais ressalta a normativa a insustentabilidade do modelo de mercado de trabalho espanhol mencionando os dados da última Pesquisa

$212 \mathrm{O}$ mencionado Pacto Mundial para o Emprego se refere à necessidade de se respaldar as empresas, em particular as pequenas, médias e microempresas para que consigam enfrentrar as mudanças sócio-econômicas advindas da globalização. Veja-se: OIT. Pacto Mundial para o Emprego. Genebra, 2009, p. V. Acessado em: 07.05.2012. 
de População Ativa realizada naquele país e que descrevia a cifra do desemprego que atingia à época de sua publicação um contingente de 5.273.600 de pessoas com um incremento de 295.300 no quarto trimestre de 2011 e de 577.000 com respeito ao mesmo trimestre de 2010, o que equivale, em termos quantitativos, a $22,85 \%$ da população ativa espanhola desempregada sendo que a situação dos jovens com menos de 25 anos de idade era todavia mais grave, já que o percentual de desemprego era de 50\%. Também, de acordo com o Real Decreto-Ley 3/2012, os problemas do mercado de trabalho longe de ser conjunturais são estruturais, afetando, por tanto,

[...] los fundamentos mismos de nuestro modelo sociolaboral y requieren una reforma de envergadura, que, pese a los cambios normativos experimentados en los últimos años, continúa siendo reclamada por todas las instituciones económicas mundiales y europeas que han analizado nuestra situación, por los mercados internacionales que contemplan la situación de nuestro mercado de trabajo con enorme desasosiego y, sobre todo, por los datos de nuestra realidad laboral, que esconden verdaderos dramas huma$\operatorname{nos}^{213}$. Las cifras expuestas ponen de manifiesto que las reformas laborales realizadas en los últimos años, aún bienintencionadas y orientadas en la buena dirección, han sido reformas fallidas (ESPANHA, Real Decreto-Ley 3/2012, 2012, p. 12483).

O Real Decreto-Ley 3/2012 214 além de reformular em seu artigo $5^{\circ}$ o trabalho a tempo parcial compreendido anteriormente no Texto Refundido da Lei do Estatuto de los Trabajadores (normativa aprovada pelo Real Decreto Legislativo 1/1995), cria, entre outras, algumas medidas para favorecer a empregabilidade, diminuir as indenizações pela extinção do contrato de trabalho, incrementar a flexibilidade interna nas empresas como alternativa a massiva destruição de postos de trabalho, modificando, por fim, a Ley 36/2011 que regula a jurisdição social (aquela que trata de julgar as ações provenientes das relações de trabalho).

Uma análise crítica da atual conjuntura do mercado de trabalho Espanhol refletida no Real Decreto-Ley 3/2012 demonstra que o trabalho a tempo parcial não melhora, ou pelo menos até o presente momento não melhorou, a qualidade do trabalho para as trabalhadoras e os trabalhadores e, nem tão pouco, evitou o desemprego massivo, pois segundo a mais recente pesquisa realizada pelo Instituto Nacional de Estatística Espanhol, os índices de desemprego no primeiro trimestre de 2013 continuam crescendo atingindo um percentual alarmante de $27,16 \%$ da população ativa

213 Grifos da autora e do autor.

214 Uma análise das alterações que o Real Decreto-Ley 3/2012 provocou nas normas concernentes ao contrato de trabalho e, em particular, sobre as normas de extinção do contrato de trabalho se encontra em: STOLZ e GALIA (2013). 
e $57,2 \%$ da juventude 215 .

A solução de compromisso da flexisegurança que visualizava na flexibilidade da relação de trabalho (e também da jornada de trabalho) uma perspectiva de aumento quantitativo dos postos de trabalho o que acarretaria, por conseguinte, o efetivo combate ao desemprego e, na segurança, a qualidade dos empregos e a respectiva igualdade de direitos no que tange às prestações da Previdência e Assistência Sociais, ainda está longe de lograr êxito naquela realidade.

A precariedade do trabalho a tempo parcial é visível e quantificável seja porque a maior parte das trabalhadoras e dos trabalhadores a tempo parcial constituise de mulheres (o trabalho a tempo parcial está relacionado com o tema da igualdade de gênero - posto que $3 / 4$ partes deste tipo de trabalho é exercido por mulheres ${ }^{216}$ ), jovens, trabalhadoras e trabalhadores com pouca qualificação profissional e pessoas afastadas há algum tempo do mercado de trabalho. Nesse sentido, entre a realidade legal do trabalho a tempo parcial e a sua realidade social, há muitas arestas que ainda precisam ser enfrentadas, particularmente no que concerne a garantia de que haja uma maior proteção das trabalhadoras e dos trabalhadores nesse tipo de contrato de trabalho.

Os temas objetos deste estudo remetem, necessariamente, as ponderações de Robert Castel inscritas no clássico livro Las metamorfosis de la cuestión social. Una crónica del salariado (1997) e no qual analisa o processo de metamorfose da "questão social" 117 concernente ao "estatuto do trabalho" e ao "estatuto do indivíduo" - que vai desde o século XVII passando pelo que denomina "a excepcionalidade da relação salarial moderna" e "a excepcionalidade da emergência do indivíduo moderno" para desembocar, na atualidade, na "nova questão social" e na consequente "desafiliação" caracterizada pela ausência de participação dos indivíduos em alguma atividade produtiva e seu respectivo isolamento relacional.

Quiçá tenham razão Umberto Romagnoli (2007), presidente da Associação Italiana de Direito do Trabalho e Previdência Social, seguido, entre outros, pelos professores laboristas espanhóis Antonio Baylos e Joaquín Pérez (2009) ao afirmarem que o projeto de flexisegurança elaborado pela União Européia tem as propriedades de um analgésico subministrado com o intuito de que se obedeçam aos ditames de uma ética opaca. Ética que serve para amortizar os danos sociais produzidos pelo retorno as épocas em que o princípio da igualdade formal entre as partes

215 Dados gerais do EPA (Primeiro trimestre de 2013): Taxa de desemprego: 27,16\%. Taxa de desemprego juvenil: $57,2 \%$. Taxa de desemprego femenino: $27,61 \%$. Taxa de desemprego masculino: 26,78\%. Domicílios em desemprego: 1.906.100. Empregos destruídos: 322.300 . População Ativa: 22.837.400. Veja-se mais em: Espanha. Encuesta de Población Activa (EPA). Primer trimestre de 2013. Madrid: Instituto Nacional de Estadística, 2013. Disponível em: http://www.ine.es/daco/daco42/daco4211/epa0113.pdf. Acesso em 15 de julho de 2013.

216 Sobre a realidade espanhola veja-se José Antonio Baz Tejedor, 2008.

217 Para Castel, a "questão social" mantém relação essencial com o trabalho, entendido este último, como "suporte" principal do indivíduo e como fator de coesão social. 
dominava o contrato de trabalho. Não obstante, faz-se imprescindível continuar reivindicando a importância social, econômica e jurídica do trabalho como forma de existência - que necessariamente deve ser digna - da maioria da população mundial e, assim sendo, uma conditio sine quanon do desenvolvimento de uma cidadania plena e cosmopolita ${ }^{218}$.

\section{REFERÊNCIAS}

AGETT e CEPREDE. Flexiseguridad laboral en España. Madrid: 2009. Disponível em: http://www.agett.com/servicio/informes/Flexiseguridad\%20laboral\%20en\%20 Espa\%F1a\%202009.pdf. Acessado em: 30.04.2012.

ARUFE, Alberto Varela. La regulación de los contratos de trabajo a tiempo parcial y a plazo en Alemania. Estudio comparativo con la regulación de los contratos precários em España. La Coruña: Anuario de La Facultad de Derecho de la Universidad de La Coruña, n. 11, 2007, p. 71-80.

BANCO DE ESPAÑA. La Flexiseguridad como modelo para los mercados de trabajo europeos. José González Mínguez e Carlos Vacas (Ed.). Madrid: Boletín Económico 86, noviembre, 2007, pp. $70-86$.

BAYLOS, Antonio e Pérez, Joaquín Rey. El despido o la violencia del poder privado. Madrid: Trotta, 2009.

BAZ TEJEDOR, José Antonio. El principio de igualdad, no discriminación (y proporcionalidad) en el trabajo a tiempo parcial. In Baz Rodríguez, Jesús. Trabajo a Tiempo Parcial y Flexiseguridad (Estudios en El Marco del Debate Europeo Modernizar el Derecho Laboral para Afrontar los Retos del Siglo XXI). Granada: Comares, 2008, pp. 37-84.

BRASIL. Decreto $n^{\circ} 7721$, de 16 de abril de 2012. Disponível em: http://www.planalto.gov.br/ccivil_03/_Ato2011-2014/2012/Decreto/D7721.htm. Acessado em: 10 .04.2012.

CASTEL, Robert. Las metamorfosis de la cuestión social. Una crónica del salariado. Tradução de A. Mailló. Buenos Aires: Paidós, 1997.

De la exclusión como estado a la vulnerabilidad como proceso. Archipiélago: Cuadernos de crítica de la cultura, n. 21,1995, pp. 27-36.

CONSELHO EUROPEU. Diretiva 97/81/CE. Disponível em: http://eur-lex.europa. eu/LexUriServ/LexUriServ.do?uri=CELEX:31997L0081:PT:HTML. Acesso em 02 de maio de 2012.

Diretiva 1999/70/CE. Disponível em: http://eur-lex.europa.eu/LexUriServ/ LexUriServ.do?uri=CELEX:31999L0070:PT:HTML. Acessado em: 02.04.2012.

ESPANHA. Real Decreto-Ley 3/2012. Madrid: BOLETÍN OFICIAL DEL ES-

218 Veja-se mais em: STOLZ (2009). 
TADO, Sec. I., 2012, p. 12483-12546. Disponível em: http://www.boe.es/boe/ dias/2012/02/11/pdfs/BOE-A-2012-2076.pdf. Acessado em: 10.04.2012.

Real Decreto Legislativo 1/1994. Disponível em: http:/www.boe.es/aeboe/ consultas/bases_datos/doc.php?id=BOE-A-1994-14960 Acessado em: 10.04.2012.

Real Decreto 1131/2002. Disponível em: http://www.boe.es/boe/ $\overline{\operatorname{dias} / 2002 / 11 / 27 / p d f s / A 41643-41650 . p d f ~ A c e s s a d o ~ e m: ~ 10.04 .2012 . ~}$

HERNÁNDEZ, Maria Luisa Martín. La protección social de los trabajadores a tiempo parcial en el nuevo marco de la $<<$ flexiseguridad $>>$. In Baz Rodríguez, Jesús. Trabajo a Tiempo Parcial y Flexiseguridad (Estudios en El Marco del Debate Europeo $<$ Modernizar el Derecho Laboral para Afrontar los Retos del Siglo XXI $>$ ). Granada: Comares, 2008, pp. 151-184.

KOK, Wim. Alargar a União Europeia. Realizações e Desafios. Bruxelas, 2004.

LEE, Sangheon; McCANN, Deirdre e MESSENGER, Jon. Working Time Around the World. Trends in working hours, laws and policies in a global comparative perspective. London-New York/Geneve: Routledge/OIT, 2007. Disponível em http:// www.ilo.org/wcmsp5/groups/public/@dgreports/@dcomm/@pub1/documents/publication/wcms_104895.pdf. Acesso em 12 de agosto de 2012.

MARTÍNEZ MOYA, Juan. El tiempo de trabajo: una visión jurisprudencial. Madrid: Revista Del Ministerio de Trabajo y Assuntos Sociales, n. 38, p. 67-93.

OCDE. OECD Employment Outlook: Moving Beyond the Jobs crisis. Paris: OCDE , 2010. Disponível em: http://www.oecd-ilibrary.org/employment/oecd-employment -outlook-2011_empl_outlook-2011-en. Acessado em: 07.05.2012.

OIT. Convenção . $^{\circ}$ 175, sobre Trabalho a Tempo Parcial. Genebra, 1994, p. 1. Disponível em: http://www.gddc.pt/siii/docs/rar37-2006.pdf Acessado em: 01.04.2012.

Pacto Mundial para o Emprego. Genebra, 2009. Disponível em: http://www. ilo.org/jobspact/lang--en/index.htm. Acesso em 07 de maio de 2012. Pacto Mundial para o Emprego. Genebra, 2009. Disponível em: http://www.ilo.org/jobspact/lang-en/index.htm. Acessado em: 07.04.2012.

ROMAGNOLI, Umberto. ¿Un Arca de Noé para el derecho del trabajo? Tradução de José Luis López Bulla e Antonio Baylos. In: Lección inaugural del curso italo-latino-americano para expertos en los problemas laborales. Bolonha: OIT, Universidad de Bolonia e Universidad de Castilla La Mancha, 2007.

SOMAVIA, Juan. O Fórum da OIT sobre Trabalho Digno para uma Globalização Justa. Lisboa: OIT/Lisboa, ano 5, newsletter 14, março 2008. Disponível em: http:// www.ilo.org/public/portugue/region/eurpro/lisbon/pdf/newsl_14.pdf Acessado em: 28.05.2012.

STOLZ, Sheila. Lo que se globaliza y lo que no se globaliza: algunas acotaciones sobre la Globalización y los Derechos Humanos. In: Stolz, Sheila e Kyrillos, Gabriela (org.). Derechos Humanos e Fundamentales. O Necesario Diálogo Interdisciplinar. 
Pelotas: Editora da Universidade Federal de Pelotas, 2009, p.p 155-166.

STOLZ, Sheila e GALIA, Rodrigo Wasem. As vicissitudes das normativas legais Espanholas referentes à extinção do contrato de trabalho. In: Torres, Artur (org.). Direito e Processo do Trabalho. Escritos em homenagem aos 20 anos de docência do Professor Gilberto Stürmer. Porto Alegre: Arana, 2013, pp. 353-377.

TANGIAN, Andranik. (2008). On the European Readiness for Flexicutiry: Empirical Evidence with OECD / HBS Methodologies and Reform Proposals. WSIDiskussionspapier Nr. 160. April 2008. Disponível em: http://www.boeckler.de/pdf/p_wsi_diskp_160_e.pdf. Acesso em: 20.05.2012.

TANGIAN, Andranik. (2004). Defining the flexicurity index in application to European countries. Diskussionspapier Nr. 122. Disponível em: http://www.boeckler.de/ pdf/p_wsi_diskp_122.pdf. Acesso em: 20.05.2012.

WILTHAGEN, Ton. The Concept of "Flexicurity": A new approach to regulating employment and labour markets. University of Amsterdam. Disponível em: http:// www.tilburguniversity.edu/ Acesso em: 27.05.2012.

WILTHAGEN, Ton e TROS, F.H. The Concept of Flexicurity: A New Approach to Regulating Employment and Labour Markets. New York, Social Science Research Network -SSNN, 2008. Disponível em: http://papers.ssrn.com/sol3/papers.cfm?abstract_id=1133932. Acesso em: 27.05.2012. 